\author{
ANNALS OF THE \\ UNIVERSITY OF CRAIOVA
}

Series: $\checkmark$ Biology

$\checkmark$ Horticulture

$\checkmark$ Food products processing technology

$\checkmark$ Environmental engineering

Vol. XXVI (LXII) - 2021

\title{
AN INITIAL STUDY ON BUSINESS CLUSTERS IN THE CONTEXT OF TERRITORIAL DEVELOPMENT
}

\author{
Goulas Apostolos ${ }^{1 \& 2^{*}}$ \\ ${ }^{1}$ Department of Agriculture - Agrotechnology, University of Thessaly, Geopolis Campus, \\ 41500 Larissa, Greece \\ ${ }^{2} H O R T L A B$, Horticultural \& Soil Resources Laboratory, University of Thessaly \\ * Correspondence author: E-mail: goulasap@yahoo.com
}

Keywords: business clusters, territorial development, cooperation, local development

\begin{abstract}
In this research paper will be presented the various forms of cooperation and coordination that exist in the international literature and reality. The study of the literature and the comparative analysis of the various forms of cooperation, as they exist and are presented, aims to highlight the different goals that each case has separately, in order to check the main research question posed in the context of territorial development. In addition, in this research paper an attempt will be made to map the forms of cooperation and the study of international experiences. It is a fact that regarding the business clusters there are in the literature many studies with different approaches and for this reason an attempt is made to present in detail the different definitions and approaches. The presentation of the various international experiences for the existing business clusters, is useful for the observation and recording of different perceptions, trends and behaviors depending on the local tradition, culture and heritage in business and cooperation. The effort to move to a new form of cooperation and coordination in the context of territorial development will then be presented. The structural differences between the classical business cluster and the business cluster are presented in detail and studied in the broader context of ensuring a new strategy for business competitiveness.
\end{abstract}

\section{INTRODUCTION}

Change in international business and the global market is a reality. The changes of recent years, and the transition to industrial society initially and to the globalization of markets and the enormous technological development then one can say that they have shaped a different way of thinking and acting, expanding markets and presenting new opportunities for those who were ready to cope with their call. Thus, in recent decades, global business giants have been created, which, taking advantage of globalization and the opening of markets and borders, have adapted their strategy and literally consolidated their global dominance. Western countries, which had a well-developed infrastructure network, were able to implement economies of scale and achieve competitive prices for their products, which are now flooding the world market. In other words, they took advantage of their competitive and comparative advantages to dominate global markets. Contributing to increasing competitiveness both between countries and between companies. All this sequence of events and developments, as well as continuous technological changes and 
discoveries, led countries and companies, along with academia, to find and implement the appropriate strategy that would give them a competitive advantage over their opponents as well. it would also extend its retention time. This resulted in the creation of an entire science, economics and administration branch, followed by different schools of thought and approach to business collaboration.

\section{WHAT IS REALLY STRATEGY}

According to Papadakis V. (2002), the concept of strategy was introduced into the vocabulary of researchers in the field, when it became clear that 'companies that competed in the same industry and used the same technology, often had remarkably different levels of performance. A closer look at the phenomenon showed that companies in the same industry often took different approaches to their products, their markets, the distribution channels they used, and even their internal structures and systems. These differences within the same sectoral environment are becoming known as strategies. '

Certainly, however, the word and the meaning of strategy have been known to mankind since the time of the Ancient Greeks, since the origin of the word has its roots in ancient Greece. While, in many historical texts there is a reference to the application of a specific strategy by the winners in historical battles.

Since then, many academics have defined strategy, such as Ansoff I., (1985), defined as the strategy the common line between the organization's activities and its products or markets, which determine the basic nature of business before, now and in the future. Andrews K., (1971), among others, states that 'strategy is a formulation of a mission, goals or objectives and policies and plans to achieve them, formulated in such a way as to determine the scope of business activity and the identity of the company While the American academic Porter M., (1980), defined as a strategy to do different things from your competitors or to do exactly the same things but in a different way. Furthermore, Johnson et al., (20006), defined as a strategy the direction and the object of the organization in the long run, through which it achieves an advantage in a changing environment through the process of shaping its resources and skills, in order to fulfill the expectations of the shareholders of the organization.

It is easy to understand that the reflection and study of academics on the strategy and the achievement and maintenance of competitive advantage has led to the development and deepening of the relevant science. Always combined with the existence of successful examples, the concept of strategy has been established in the global firmament and despite the fact that no one can claim with certainty that success is guaranteed by its adoption and implementation, it certainly contributes to achieving business goals. . Papadakis V., (2002), in fact mentions in this regard the main reasons why this happens, which are:

- Strategy sets directions

- The strategy supports uniform decision making

- The strategy concentrates the effort and coordinates activities

- The strategy defines the business and its position vis-.-Vis the competition

- Strategy reduces uncertainty

- Strategy can provide a sustainable competitive advantage.

Also, according to Mintzberg H., (1987) strategy is a complex concept and needs more analysis, while it can be approached in the light of the following five dimensions: design, trick, model, attitude and perspective. Then, Papadakis V., 
(2002) summarizes by concluding that 'strategy leads to consistent - coherent decisions ensuring the coherence of a company, sets directions, defines the company, reduces uncertainty, concentrates effort and finally provides a sustainable competitive advantage. Hunger D., and Wheelen Th., (2004) also spoke about the importance of strategy, emphasizing that strategy is the set of management decisions and actions that determines the long-term performance of the company. Therefore, the adoption and implementation of the strategy by organizations, private and non-private, is aimed at achieving long-term sustainability, while as explicitly stated by Fleisher C., and Bensoussan B., (2003) strategy is a dynamic process, and this makes a clear definition difficult. The reason this happens is that everything in the business environment changes, such as time, technology, markets, competition rules, and even competitors are not the same. Therefore, the strategy cannot remain the same all the time. And that's the big bet for most organizations, big or small, private or not, to always have the right strategy so that they can stay competitive. Moreover, as reported by Fleisher C., and Bensoussan B., (2003), the world economy is no longer an industrial economy, as it was in recent decades, but is characterized as a knowledge economy, since now most of the Gross National Product of The world's major economies are made up of services and intangibles, and the services provided are more cognitive than material. As a result, the knowledge economy means for companies and organizations that they need to further develop their unique capabilities, resources, competencies and specialization, in order to be able to maintain a competitive advantage.

\section{BUSINESS CLUSTERS}

The ever-changing business environment and the market conditions in which companies operate, creates, as mentioned above, the need to achieve and maintain a competitive advantage. This has led to the creation and spread of business networks and partnerships between companies. Mainly small and mediumsized enterprises, which want to remain competitive, enter new markets, invest in research and development and even become global players themselves, must establish appropriate partnerships with other companies. The question therefore arises, what is the form that such cooperation should take. How will it be organized, how will it be able to operate and become sustainable and competitive in the globalized market?

According to the international literature, the first to realize the importance of developing business cooperation was Marshall A., (1890) who referred to industrial districts. In fact, in this text, he supported the importance of the concentration of specialized industries in a specific area, as well as the benefits that arise for them, from these concentrations. According to Alberti F. (2001) in his observations on the industrial areas of Marshall A., in these areas are active small - mainly local companies, which often develop partnerships with each other often with long-term contracts, while partnerships with companies outside the industrial area are limited. Owners and workers coexist harmoniously and live in the same community, in the same working environment, thus creating a strong and stable bond, which allows the creation of a strong local identity but also the diffusion, always within the industrial area, of industrial authority and knowledge.

However, several years later, the modern pioneer of strategic management, the American Porter M., (1990) first introduced the concept of cluster business, also known internationally as clusters. This approach has really greatly influenced and 
changed the way of thinking globally in terms of the strategy of both companies and the Nations themselves. Thus, Porter defined as clusters of 'geographically close', interconnected groups of companies and collaborating institutions in specific areas, which are connected through common technologies and capabilities. Their operation in the same geographical area facilitates communication, transports, but also possibly personal interaction. Clusters are usually focused on regions and are sometimes limited to a single city in the region. ' This group of neighboring and interconnected companies cooperates with agencies and institutes of a specific sector, while the group companies are associated with common and complementary goals. This definition is the most common and has been the basis for many academics to continue their research on business clusters and grouping. In fact, there is an international effort to create and develop policies at both international and national level, with the sole purpose of highlighting partnerships between companies and mainly small and medium-sized enterprises.

Looking, therefore, at the relevant literature, it is easy to understand that clusters as a concept have occupied many academic and business circles as a basic model of development. In addition to Porter and the definition presented above, Doeringer and Terkla (1995) respectively defined industrial clusters as "the geographical concentrations of industries which gain advantages in their performance through their proximity". Continuing the logic of geographical links between companies participating in a cluster, Rosenfeld (1997) highlighted relevant or complementary activities, with active channels for business transactions, communications and dialogue, with specific shared infrastructures, markets and services being addressed. with common opportunities and threats. While Polyzos S., (2011), argues that 'the term clusters' means the groups of companies, branches and institutions, which are usually located in the same geographical area, specialize in a specific field of productive activities and are interconnected with specific common and complementary characteristics'. To continue in the same text and emphasize that 'these concentrations, which are due to the strong phenomena of diffusion of knowledge, experience and complementarity of skills, which enhance the degree of innovative action, improve technological knowledge and business competitiveness'.

It is easy to understand that there is a lot of interest in the issue of clusters of companies but there are also many different approaches. But what is common to all definitions, is the importance of the geographical area but also the strong links that develop between the companies involved in the cluster. The spatial proximity but also the trust between the companies of the cluster facilitate and enhance the continuous and safe movement of raw materials, knowledge, information and knowhow. As Doz et al. (2001) aptly state in their book, geography is destiny. If your business was located in the right geographical area, country or region, the omen of global success was favorable, while it could well achieve and maintain a competitive advantage over even aggressive multinational rivals. In fact, Michel Porter in his book The Competitive Advantage of Nations, calls these areas as diamond clusters, since the location of the cluster, in a 'suitable' area, gives it and the companies that are its competitor advantage over competitors located in other less 'suitable' areas. In fact, this is not an impression, since even traditional multinational companies use their cluster headquarters as a source of competitive advantage.

Therefore, the English economist Alfred Marshall, who was the first to speak about industrial areas in a specific place with specific characteristics, the American 
academic Michael Porter, who was the first to speak about the importance of creating business clusters in a specific country or region and the rest of the academics the importance of the place, in achieving and maintaining a competitive advantage.

\section{INTERNATIONAL EXPERIENCES}

This section will present some examples from the international literature, which show the evolution and understanding of the concept of networking around the world. In fact, the concept of networking is approached differently in each case and it is very important at this point to study and present each approach separately in order to better understand the concept of networking.

Keiretsu

Japan is a country with a long tradition and is characterized by its technological achievements and innovations, mainly in the field of heavy industry, such as the automotive industry, but also in high-tech products, such as computers, mobile phones, televisions and others. It is a fact that the economic model of Japan is of great interest in general in combination with other factors such as culture, the special Japanese approach to many issues and entrepreneurship.

Taking into account the peculiarities of Japan as a country, both socioeconomic and political, from the Second World War onwards, and analyzing the structure of their economy and the basis of their development, the researcher often encounters the term Keiretsu. Essentially, these are groups of companies that are interconnected in order to achieve a competitive advantage over their competitors, economies of scale, better distribution networks and global business activity and presence. In essence, Keiretsu, and here is the most significant difference with the business clusters presented above, is a group of companies that gather around a bank or a venture capital company, with specific shares and business relationships, trying to achieve a common goal. . In fact, Evelyn Anderson (2007) argues that this post-war phenomenon first appeared in the Japanese automobile industry and as a term first appeared in July 1952 when the country's small and medium-sized enterprises presented a pioneering development program for its time, known as Keiretsu Shindan. . This program, which in free translation means diagnosis of Keiretsu, had the following objectives (Anderson E., 2007):

- investigate the extent to which car assembly companies were dependent on their network vendor, as well as the extent to which suppliers could meet the management needs of their customers

- study how the relationship with suppliers has affected the management of both parties

- analyze and manage the complementarity relationship between car assembly companies and their network suppliers

- identify specific features and areas for improving this relationship

- improve transaction methods between the two parties based on the findings of the diagnosis

- provide guidelines for component suppliers

- overcome the problems of companies under capitalization and lack of input, promote cooperation between assembly companies and suppliers, and improve general management

- increase the financial situation of component suppliers, which were mainly Japanese small and medium enterprises. 
The above proposals but also the domestic and global circumstances created the Keiretsu phenomenon which contributed decisively to the creation of the Japanese giant, while it came to become synonymous with all the cooperatives of Japan and especially those of the automotive industry. While according to Ahmadjian Ch., And Lincoln J., (2001), the Japanese business complexes, also known as Keiretsu, allowed the domestic automakers, in particular, to remain flexible and competitive while at the same time enjoying some control over the part of the tender which was related to the vertical integration. Finally, James Ricks (1993) defined the Japanese business clusters discussed in this chapter as 'a channel and distribution approach that emphasizes the relationships between the companies involved. The Japanese economic model has the following peculiarity, a company with leading characteristics is selected to take the initiative and make the rest follow in the creation of the cluster and in synergies. Essentially, the rest of the companies are grouped around the company with the leading characteristics since it acts as a catalyst and sets the directions and goals.

However in the case of Keiretsu, as in business clusters, there are horizontal Keiretsu as well as vertical Keiretsu. Looking at the relevant literature, one realizes that most academics have dealt extensively with both horizontal and vertical Keiretsu. In fact, as Lincoln RJ and Shimotani M. (2009) argue, in both horizontal and vertical Keiretsu, the links that unite businesses are generally the same, that is, with cross-stakes, staff transfers. from one company to another but also of the preferred companies. Despite the similarities and commonalities between the horizontal and vertical Japanese business clusters, there are also significant differences. An important parameter is the one mentioned by Dow Sandra, McGuire Jean and Yoshikawa Toru (2009). In particular, they claim that with the growth of the globalization of the capital markets and the recent global financial crisis, the financial stability of the horizontal Keiretsu has been significantly affected. In addition, Dow et al., (2009) argue that horizontal Japanese business clusters, with strong business links, are more resilient to any changes from the external environment.

Another difference between vertical and horizontal Japanese business clusters, according to McGuire J ,. and Dow S., (2009) is that the structure of the Keiretsu verticals is asymmetric with respect to that of the horizontal ones, which is clear with the core company and its main suppliers at the center of the network. However, most studies conclude that the global financial crisis has raised serious concerns about the operation and future of Keiretsu, even if participation in them provides several benefits such as reducing market pressures, reducing risk, reducing of asymmetric information and their evaluation, mutual assistance.

Italian Industrial Area

One model that bears several similarities to the Japanese model of the Keiretsu is the one that appeared and developed in Italy, known in the world literature as the Italian Industrial Area. It can be said that the Italian Industrial Areas are an evolution of the Industrial Areas as proposed by Alfred Marshall.

'The phenomenon of Industrial Areas has been observed in several European countries and especially in Italy, where it was initially recognized' (Bartellotti R., pp. 29, 1995). In fact, as she argues, the context of Industrial Areas has led academics and economists to believe that there is a clear model, with specific characteristics and clear elements, which can be applied in any case and in any country. While this model is not a detailed model, but a list of useful facts and steps, which effectively organize empirical studies and lead to comparisons with real 
cases from around the world. However, the Italian academic Giacomo Becattini, obviously influenced by Alfred Marshall and his views, studied the phenomenon and dared to speak in his research on the Industrial Areas and the conditions for local economic development. In fact, he said that the industrial system in general should be divided into each sector in order to be able to better study it. This separation of each sector separately creates those conditions that will contribute to the creation of Industrial Zones. Giacomo Becattini (2004) then argued that 'Industrial Areas as envisioned by Marshall have an' industrial atmosphere ', which is both the source and the result, the purpose, and the influence, is the element that which cannot be explained or measured by economies of scale or by research and development. It is this extra element in the production process that makes yesterday's Lombardia, like today ' $s$ ' Third Italy ', stand strong against their competitors.' The 'industrial atmosphere', then, of Alfred Marshall is the element that essentially intersects the Japanese proposal of the Keiretsu, with the Italian proposal of the Industrial Zones. It is the special element that exists in the tradition of these peoples, it is inextricably linked to the place and there are generations and generations who have been nurtured with this mentality. One can claim that it is connected with history, tradition, culture and place. Moreover, for the existence of the 'Industrial Areas', as several academics have argued, the key features are the existence of geographical proximity, sectoral specialization, the predominance of small and medium-sized enterprises, close cooperation between the companies constituting the 'Industrial Area', competition for innovation of the companies that constitute the 'Industrial Area', an active municipal and regional administration which stimulates the innovation and entrepreneurship of the local industries. However, it should be noted that depending on the 'Industrial Area' the weight and importance of the above variables changes '(Shcmitz H., and Musyck B., pp. 890, 1994). At the same time, however, there are many academics (Garofoli G., 1983a, Garofoli G., 2009b, Garofoli G., 1999c, Courlet C. and Pecqueur B., 1991) who spoke of a 'local productive system' or a ' socio - territorial industrial system ', with the main feature of these systems, their unique ability to create cooperative clusters with clear social and economic conditions of cooperation between the companies and entities involved. While it is recognized that in all these proposals and methodologies the focus is on the region.

The fact that brought to the fore again after so many years the 'Industrial Areas' and their importance for the development, innovation and competitiveness of companies but also the areas where they exist and operate is mainly the model of 'Third Italy' and the impact it had on the international literature. It is characteristic that the Italian academic community has particularly developed research and reflection on the various systems for small local businesses, also known as 'Industrial Areas' (Garofoli 1981, Garofoli 1983, Garofoli 1999). In fact, as Gioacchino Garofoli (1999) argued, 'this model emphasizes the characteristics of production organization, which is in contrast to the model of large enterprises and' growth from above 'where the logic of division of labor related to technical and organizational needs, which are delimited by the company - leader of the 'Industrial Area' and is a common and inviolable principle for all companies involved. The 'Industrial Areas' model denies the validity not only of the number of theoretical hypotheses in general (and often indiscriminately) which have been accepted (the principle of a gradual increase in performance applies to all the companies involved in the 'Industrial Area'), but also the guidelines pursued by the individual regional development policies (but also the 
tout - court development) followed not only in developed countries but also in developing ones'.

In addition, Gioacchino Garofoli (1999) argued that: 'the' Industrial Areas' model contrasted with a long tradition of 'operating' type economic models, which play a key role in growth in the presence of economic functions. as well as developed economic sectors thus predetermining a hierarchy between countries as well as a sequence of development stages which any country wishing to develop must follow. Territory in the approach to operation plays only a passive role, as economic development is a process 'objectively predetermined' by the presence of the following technical components. There is no room for subjectivity, there is no active role for development social actors, there are no opportunities for alternative paths of growth and transformation, the process of innovation is also a purely technical phenomenon. ' While continuing to emphasize that: 'the analysis of the production organization of the' Industrial Zones' as well as the social factors that underlie them, allows to shed a lot of light on the new variables that reflect a relative importance in the decisions (of the choice of place the choice of investment, the choice of strategies) of economic operators. This has the effect of influencing the transformation processes of the local economy (and society) as well as of their upper territorial clusters, the relations of cooperation between enterprises, the relations between the productive system and the socio-institutional system, professionalism and participation. of employees in the organization of business production as well as in the global model of the wider region, the special role of local institutions that intervene in the immediate resolution of certain deficiencies (or 'failures') of the market (technology centers, service centers, vocational training schools, local and regional development organizations). In other words, it organizes a social system of correlations, the circulation of information, the production and reproduction of the values it permeates, and characterizes the mode of production that has been adopted. '

"Third Italy"

While always referring to the case of the 'third Italy' and the relevant research of Becattini, for the creation of a widespread model of industrialization which will aim at development, combining urban with rural centers as well as a collaborative family processing culture, the Colletis K ., and Pecqueur B., (2001) state that spatial proximity (short distances between production centers) facilitates the movement of goods and information, as well as the specialization of operators during the production process, which tends to become collective, without however being entirely / exclusively collective. It is therefore easy to understand that deeper concepts such as tradition, timelessness, synergies and collectivity are part of the broader context of this particular development model. Whereas, the proximity and spatial 'proximity' between the contracting companies is considered a given, with the sole purpose of the real and obvious benefits arising from the specific collaborative actions and efforts. However, according to Ron Boschma (1999), social capital also plays a key role in the 'third Italy' model and in regional economic development. Which Ron Boschma (1999) then defines as those characteristics of social organization, such as trust, rules and networks that improve the efficiency of society, while facilitating the achievement of coordinated actions and common goals'.

Therefore, the model developed in Italy, gave weight to the social dimension and social capital, in addition to other characteristics, along with tradition and specialization. This is a feature that gave comparative and competitive advantage to 
the small traditional Italian companies that needed to stand in both the domestic and global market.

\section{Economic networks}

However, in addition to the above, in the relevant international literature with models of development between companies and partnerships, one also encounters financial networks. According to a study conducted by the National Observatory for Small and Medium-sized Enterprises, "financial enterprise networks are at least three companies that enter into a joint employment contract to implement actions from the outset within a specific time frame". Usually, economic networks are governed by strategic alliances, agreements for the transfer and exchange of knowhow, for joint research and development. While in this case, as in the case of Keiretsu, networking between companies is done on the initiative of one of the companies, which assumes the leading role in the financial network, over the others, which follow. It is worth noting that several times, an economic network evolves into a business cluster, since the characteristics of partnership and collaboration have been cultivated steadily and gradually.

These forms have contributed to the creation of economies of scale. While any links with the place exist, they created skilled personnel and essentially contributed to them becoming industrial areas. However, this process did not contribute to the connection of the place of business with the raw material and its special characteristics. The product produced, which is ultimately produced by the specific business clusters, has nothing to do with the particular characteristics of the place but with the unique skills developed within the business cluster. This has the consequence, whenever deemed necessary (for reasons of easier access with the raw material, easier access with suppliers and the market, for tax reasons, etc.) the business cluster has the flexibility to move to another place and to continue to produce the same product, remaining unaffected by the change of installation location.

\section{REFERENCES}

Ahmadjian Christina and Lincoln James, (2001), 'Keiretsu, Governance, and Learning: Case Studies in Change from the Japanese Automotive Industry', Organization Science, Vol. 12, No. 6, November - December 2001, pp. 683 - 701.

Alberti F., (2001), 'The Concept of Industrial District Main Contributions'.

Anderson E., (2007), 'Nissan's keiretsu 1956 - 1970', Published in BEH online, Vol. 5, pp. $1-13$.

Bartellotti Roberta, (1995), 'Is There an 'Industrial District Model?' Footwear Districts in Italy and Mexico Compared', World Development, Vol. 23, No.1, pp. 29 - 41.

Becattini Giacomo, (2004), 'Industrial Districts: A New Approach to Industrial Change', Elgar Publishing, UK.

Boschma Ron, (1999), 'Culture of trust and regional development: an empirica

Courlet Claude and Pecqueur Bernard, (1991), 'Local Industrial Systems and externalities: An essay in typology', Entrepreneurship and Regional Development, Vol. 3, No. 4.

Colletis - Wahl Kristian and Pecqueur Bernard, (2001), 'Territories, Development and Specific Resources: What Analytical Framework?', Regional Studies, 35:5, pp $449-459$.

Doeringer, P.B. and D.G. Terkla. (1995) Business Strategy and Cross-Industry Clusters, Economic Development Quarterly, 9 (3), pp. 225-237. 
Doz Y., Santos J., and Williamson P., (2001), 'From Global to Metanational', Harvard Business School Press.

Dow Sandra, McGuire Jean and Yoshikawa Toru, (2009), 'Disaggregating the group effect: Vertical and horizontal keiretsu in changing economic times', Asia Pacific Journal of Management, Volume 28, pp. $299-323$.

Fleisher C., and Bensoussan B., (2003), 'Strategic and Competitive Analysis', Prentice Hall.

Garofoli Goacchino, (1991a), 'Modelli locali di sviluppo', Milano, Franco Angeli. Garofoli Goacchino, (1999c), 'Lo sviluppo locale: modelli teorici e comparazioni internazionali', Meridiana, nn. $34-35$, pp. $71-96$.

Garofoli Goacchino, (2009b), 'Sistemi produttivi locali e sviluppo economico'.

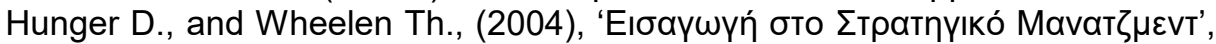

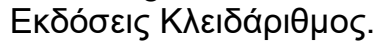

Lincoln R. James and Shimotani Masahiro, (2009), 'Whither the Keiretsu, Japan's Business Networks? How Were They Structured? What Did They Do? Why Are They Gone?'. eScholarship Repository, University of California.

Marshall A., (1890), 'Principles of Economics'.

McGuire Jean and Dow Sandra, (2008), 'Japanese Keiretsu: Past, present, future', Asia Pacific Journal of Management, 26:333 - 351.

Mintzberg H., (1987), 'The Strategy Concpet I: Five Ps for Strategy', California Management Review, pp $11-24$.

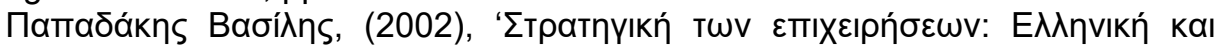

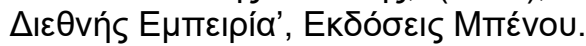

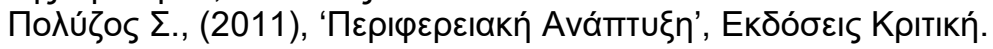

Porter M., (1990), 'The Competitive Advantage of Nations', New York: Free Press.

Rosenfeld, Stuart A. (1997). Bringing Business Clusters into the Mainstream of Economic Development, European Planning Studies, 5 (1), 10.

Schmitz Hubert and Musyck Bernard, (1994), 'Industrial Districts in Europe: Policy Lessons for Developing Countries?', World Development, Vol. 22, No. 6, pp. $889-910$. 